\title{
Morfologia externa e interna das folhas vegetativas, esporofilos e esporângios de espécies de Huperzia Bernh. (Lycopodiaceae - Pteridophyta) do Brasil ${ }^{1}$
}

\author{
PATRÍCIA B. PITA ${ }^{2,4}$, NANUZA L. DE MENEZES ${ }^{3}$ e JEFFERSON PRADO ${ }^{2}$
}

(recebido: 18 de novembro de 2004; aceito: 19 de janeiro de 2006)

\begin{abstract}
External and internal morphology of the vegetative leaves, sporophylls and sporangia of Huperzia Bernh. species (Lycopodiaceae - Pteridophyta) from Brazil). Lycopodiaceae belongs to the Lycopsida, which autapomorphy is the presence of microphyllous leaves. It was studied 10 species, and seven are endemic to Brazil: the terrestrials Huperzia christii (Silveira) Holub, H. friburgensis (Nessel) B. Øllg., H. hemleri (Nessel) B. Øllg., H. intermedia Trevis., H. reflexa (Lam.) Trevis. and H. treitubensis (Silveira) B. Øllg.; the epiphytics H. fontinaloides (Spring) Trevis., H. heterocarpon (Fée) Holub, H. hexasticha B. Øllg. \& P.G. Windisch and H. quadrifariata (Bory) Rothm. The anatomical features found that are probably adaptive to a water deficient environment are the presence of epidermal cells with sinuous anticlinal walls, invaginations in the inner side of external periclinal wall of the epidermal cells and amphiestomatic leaves. The analysed species were separated in two groups, corroborating existing classifications. The two groups were defined on the basis of the following characters: phyllotaxis helical or opposite, leaf position in relation to the stem, if reflexed or adpressed, and the number of sporangia cell layers, if three or four. An identification key was elaborated.
\end{abstract}

Key words - Huperzia, leaf, Lycopodiaceae, plant anatomy, Pteridophyta

RESUMO - (Morfologia externa e interna das folhas vegetativas, esporofilos e esporângios de espécies de Huperzia Bernh. (Lycopodiaceae - Pteridophyta) do Brasil). Lycopodiaceae está inserida em Lycopsida, cuja autapomorfia é a presença de folhas microfilas. Foram estudadas 10 espécies, sete delas endêmicas do Brasil: Huperzia christii (Silveira) Holub, H. friburgensis (Nessel) B. Øllg., H. hemleri (Nessel) B. Øllg., H. intermedia Trevis., H. reflexa (Lam.) Trevis. e H. treitubensis (Silveira) B. Øllg., estas terrestres; H. fontinaloides (Spring) Trevis., H. heterocarpon (Fée) Holub, H. hexasticha B. Øllg. \& P.G. Windisch e H. quadrifariata (Bory) Rothm., estas epífitas. As características anatômicas encontradas, que podem ser adaptativas ao ambiente com escassez hídrica são a presença de células epidérmicas com paredes anticlinais sinuosas, invaginações na face interna da parede periclinal externa das células epidérmicas e folhas anfiestomáticas. As espécies estudadas foram reunidas em dois grupos, corroborando classificações existentes. Os grupos foram definidos com base nas seguintes características: a filotaxia, se helicoidal ou oposta, a posição das folhas em relação ao caule, se reflexas ou adpressas, e o número de camadas de células do esporângio, se três ou quatro. Foi elaborada uma chave de identificação.

Palavras-chave - anatomia vegetal, folha, Huperzia, Lycopodiaceae, Pteridophyta

\section{Introdução}

Lycopodiaceae apresenta quatro gêneros: Huperzia Bernh., Lycopodiella Holub, Lycopodium L. e Phylloglossum Kunze, de distribuição cosmopolita, exceto Phylloglossum, que está restrito ao Sudoeste da Austrália, Nova Zelândia e Tasmânia (Hackney 1950, Øllgaard 1987). É constituída por cerca de 500 espécies, sendo Huperzia o gênero mais representativo, com

\footnotetext{
1. Parte da tese de doutorado do primeiro autor, Programa de Pós-Graduação do Instituto de Biociências da Universidade de São Paulo.

2. Instituto de Botânica, Divisão de Fitotaxonomia, Caixa Postal 4005, 01061-970 São Paulo, SP, Brasil.

3. Universidade de São Paulo, Instituto de Biociências, Departamento de Botânica, Caixa Postal 11461, 05508-090 São Paulo, SP, Brasil.

4. Autor para correspondência: patriciabpita@yahoo.com
}

aproximadamente 300 espécies (Øllgaard 1987). No Brasil ocorrem 52 espécies de Lycopodiaceae, 37 do gênero Huperzia, 11 de Lycopodiella e quatro de Lycopodium (Øllgaard \& Windisch 1987).

O gênero Huperzia apresenta uma alta porcentagem de endemismos. Nos Andes, das 95 espécies existentes, 69 são endêmicas, num total de $73 \%$ de endemismo, e no Brasil, das 37 espécies ocorrentes, 26 são endêmicas, num total de 68\% (Øllgaard 1996). Huperzia é o único gênero da família dividido ainda em grupos informais, e com espécies pouco definidas (Øllgaard 1987).

As Lycopodiaceae estão inseridas em Lycopsida, com Selaginellaceae e Isoetaceae (Gensel 1992, Kenrick \& Crane 1997, Pryer et al. 2001). A presença de folhas do tipo microfila, do esporângio na superfície adaxial do esporofilo e do xilema de diferenciação exarca distinguem os membros de Lycopsida das outras plantas vasculares (Gifford \& Foster 1989, Kenrick \& Crane 
1997). Além disso, as folhas microfilas, que são aquelas que apresentam uma única unidade vascular não ramificada que parte do caule sem deixar lacuna (Sporne 1966), definem a classe como um grupo monofilético (Kenrick \& Crane 1997).

As características morfológicas da folha são de suma importância para a classificação das licopodiáceas. Em Huperzia, por exemplo, as espécies foram agrupadas por Øllgaard (1987) como homofilas, gradualmente heterofilas ou heterofilas.

A maioria dos estudos em Lycopodiaceae tiveram cunho taxonômico, como os de Wilce (1972), Øllgaard (1975), Rolleri (1975), Bruce (1976) e Tryon \& Lugardon (1991). Em relação aos estudos de anatomia foliar, Rolleri (1975) utilizou caracteres anatômicos, como a distribuição dos estômatos e papilas na superfície epidérmica, para distinguir espécies; Bruce (1976) identificou canais de mucilagem acompanhando a unidade vascular das folhas vegetativas e esporofilos em Lycopodiella, canais de mucilagem localizados na base dos esporofilos em Lycopodiella e Lycopodium e ausência de canais em Phylloglossum e Huperzia.

Øllgaard (1975) fez uma análise da epiderme do esporângio em Lycopodiaceae e definiu padrões anatômicos para os gêneros. Segundo o autor, os esporângios podem apresentar a epiderme sinuosa e moderada a fortemente lignificada em Huperzia e Phylloglossum; ou paredes delgadas, sinuosas e lignificadas em Lycopodium; ou retilíneas, não lignificadas, delgadas com espessamentos lignificados semi-anelados a nodulares em Lycopodiella.

Wilce (1972) e Tryon \& Lugardon (1991) também encontraram padrões para a ornamentação da parede dos esporos nos gêneros de Lycopodiaceae: foveoladafossulada em Huperzia, rugosa em Lycopodiella, reticulada em Lycopodium e foveolada em Phylloglossum.

Estudos anatômicos mais abrangentes podem ser encontrados em Hackney (1950), Toursarkissian (1971) e Rolleri (1972), dentre outros. Hackney (1950) fez uma análise da morfologia externa e interna do esporófito de Phylloglossum drummondii Kunze, com correlações ecológicas e filogenéticas; Toursarkissian (1971) estudou morfologicamente o esporófito de cinco espécies de Lycopodiaceae, e Rolleri (1972) de oito espécies, e elaboraram chaves de identificação.

Tendo em vista a grande representatividade do gênero no país, a alta porcentagem de endemismo e os raros estudos anatômicos das licopodiáceas brasileiras, este trabalho teve como objetivo ampliar o conhecimento da morfologia do grupo, por meio da descrição comparada da anatomia foliar e do esporângio de grupos informais com espécies endêmicas do Brasil, tanto epífitas como terrestres, a fim de elucidar a delimitação das espécies e formalizar e/ou redelimitar os grupos já descritos por Øllgaard (1987).

\section{Material e métodos}

Os grupos de espécies estudadas, sensu Øllgaard (1987), são o grupo de Huperzia reflexa (Lam.) Trevis., mas somente as espécies ocorrentes no Brasil, e o subgrupo de Huperzia quadrifariata (Bory) Rothm., do grupo de Huperzia phlegmaria (L.) Rothm., que apresenta somente espécies endêmicas do Brasil. No primeiro as espécies são terrestres e no segundo são epífitas. Além destas, foram estudadas duas espécies não relacionadas aos grupos citados, para verificar a consistência dos mesmos: Huperzia treitubensis (Silveira) B. Øllg., do grupo de H. brongniartii (Spring) Trevis. e H. heterocarpon (Fée) Holub, do grupo de H. heterocarpon (Fée) Holub. Os grupos foram escolhidos por apresentarem espécies endêmicas do Brasil, todas ocorrendo no Sudeste e no Sul da Bahia, em Ilhéus, com exceção de Huperzia heterocarpon, que ocorre em Missiones, Argentina, H. reflexa, em toda a América Tropical e H. intermedia Trevis., disjunta nas Antilhas, Venezuela e no Sudeste brasileiro (Øllgaard 1992).

As espécies estudadas estão relacionadas abaixo, com os números de coletores e siglas de herbários onde as exsicatas estão depositadas. Foram utilizadas plantas fixadas e provenientes de exsicatas de herbários, que estão indicadas com asterisco. No caso da exsicata não apresentar número de coletor, foi citado o número do herbário. As exsicatas estão indicadas, abaixo, dentro de cada grupo de espécies.

Pertencentes ao grupo de H. reflexa (Lam.) Trevis., sensu Øllg. (1987): Huperzia christii (Silveira) Holub - BRASIL. RIO DE JANEIRO: Serra dos Órgãos, Brade $3069 *(\mathrm{CESJ})$; MinAS Gerais: Serra do Caparaó, Windisch $4966 *(\mathrm{SPF})$; São Paulo: Campos do Jordão, Windisch 4994 *(SPF). H. friburgensis (Nessel) B. Øllg. - BRASIL. RIO DE JANEIRO: Rio de Janeiro, L. Sylvestre $1405 b$ (RBR), $1406 b$ (RBR). H. hemleri (Nessel) B. Øllg. - BRASIL. Rio de JANEIRO: Município de Santa Maria Madalena, Parque Estadual do Desengano, M. Leitmam 324 *(RB); Santa Magdalena, Serra da Furquilha, s. col. (RB 288536*). H. intermedia Trevis. - BRASIL. MinAs GeraIs: Parque Nacional da Serra do Cipó, P. Soffiatti 39 (SPF), T. Konno 789 (SP). H. reflexa (Lam.) Trevis. - BRASIL. MinAS GerAIS: Parque Nacional da Serra do Cipó, G.F. Melo 13 (SPF), V.A. Cardoso 5 (SPF), T. Konno 783 (SP). Huperzia rostrifolia (Silveira) Holub, também pertencente ao grupo, não pôde ser analisada, pois seus dois únicos exemplares encontram-se em herbários da Alemanha e França.

Pertencentes ao grupo de H. brongniartii (Spring) Trevis., sensu Øllg. (1987): Huperzia treitubensis (Silveira) B. Øllg. - BRASIL. Minas GeraIs: Parque Florestal Estadual 
do Ibitipoca, s.col. (CESJ27346*), P. B. Pita 321*(CESJ).

Pertencentes ao subgrupo de $H$. quadrifariata (Bory) Rothm. do grupo de H. phlegmaria (L.) Rothm., sensu Øllg. (1987): Huperzia fontinaloides (Spring) Trevis. - BRASIL. São Paulo: Campos do Jordão, E.A. Rodrigues 72 *(SP). H. hexasticha B. Øllg. \& P.G. Windisch. - BRASIL. São PAULO: Campos do Jordão, J. Prado $778 *(\mathrm{SP})$, J. Prado $800 *(\mathrm{SP})$, A. Salino 5616 (BHCB). H. quadrifariata (Bory) Rothm. BRASIL. Rio DE JANEIRo: Brade $14191 *(\mathrm{RB})$; SAntA CATARInA: Parque Botânico Morro do Baú, V.L.G. Klein 3526 (FLOR); Minas Gerais: Monte Verde, L. Meireles 1203 (UEC).

Pertencentes ao grupo de H. heterocarpon (Fée) Holub, sensu Øllg. (1987): Huperzia heterocarpon (Fée) Holub. BRASIL. Rio DE JANEIRO: Serra dos Órgãos, 17/07/1940, Brade $16411 *(\mathrm{RB})$; Macaé, Pico do Frade de Macaé, M. Leitmam $57 *(\mathrm{RB})$; Minas Gerais: Parque Florestal Estadual do Ibitipoca P. B. Pita $273 *(\mathrm{CESJ})$.

Para a reidratação do material herborizado, fragmentos de caule portando folhas e esporângios foram colocados em água destilada com algumas gotas de glicerina e mantidos em estufa a $58{ }^{\circ} \mathrm{C}$, por aproximadamente $48 \mathrm{~h}$ (Chu 1974). Em seguida, o material herborizado e o material coletado foram fixados em FGAA (Lersten \& Curtis 1988), depois transferidos para etanol $50{ }^{\circ} \mathrm{GL}$ e, posteriormente, mantidos em etanol $70^{\circ} \mathrm{GL}$.

Para o estudo anatômico, folhas vegetativas, esporofilos e esporângios - localizados nas regiões apical, mediana e basal do caule - foram diafanizados, seccionados (à mão livre e em micrótomo de rotação) e macerados. Para a diafanização, utilizou-se hipoclorito de sódio comercial $50 \%$ por duas horas e o método de Strittmatter (1973), modificando-se o tempo da fervura em álcool $96{ }^{\circ} \mathrm{GL}$ e em solução de álcool $96{ }^{\circ} \mathrm{GL}$ e $\mathrm{NaOH} \mathrm{5 \%}$. O material foi corado com fucsina básica $50 \%$ em etanol $50{ }^{\circ} \mathrm{GL}$ (Kraus et al. 1998) e montado entre lâmina e lamínula com glicerina 50\%. Foram feitas secções transversais e longitudinais das folhas e fragmentos de caule com folhas e esporângios à mão, com o auxílio de lâmina de barbear, bem como em micrótomo de rotação, quando incluídas em Paraplast $®$ (Johansen 1940) e em historresina (marca Jung). A desidratação foi feita em série etílica. O material seccionado à mão livre e incluído em Paraplast $®$ foi corado com azul de astra em ácido tartárico $2 \%$ e fucsina básica $50 \%$ em etanol $50{ }^{\circ} \mathrm{GL}$ (Kraus et al. 1998) e montado em glicerina $50 \%$ e em bálsamo-do-canadá, respectivamente; o material incluído em historesina foi corado com azul de toluidina (O'Brien et al. 1965) em tampão fosfato pH 6,8 (Deutscher 1990). A maceração foi feita de acordo com Franklin (1945 apud Kraus \& Arduin 1997, modificado) e o material foi corado com safranina $1 \%$ em etanol $50{ }^{\circ} \mathrm{GL}$ (Johansen 1940) e montado em glicerina $50 \%$.
Foram feitos testes com azul de resorcina (Cheadle et al. 1953), para verificar a presença de calose; com cloreto férrico (Johansen 1940), para compostos fenólicos; com cloreto de zinco iodado (Jensen 1962), para lignina e amido; com floroglucinol acidificado (Foster 1949), para lignina; com reagente de Steinmetz (Costa 1970), para lignina, celulose, amido e substâncias lipídicas; com Sudan IV (Jensen 1962), para substâncias lipídicas, cutina e suberina.

Os resultados foram registrados em fotomicroscópio Olympus-Vanox.

As nomenclatura da morfologia da folha (homofilas, gradualmente heterofilas ou heterofilas), da epiderme do esporângio e da ornamentação do esporo baseou-se em Øllgaard (1987, 1975) e Wilce (1972), respectivamente.

\section{Resultados}

Os esporófitos de Huperzia estudados apresentam caule ramificado dicotomicamente em toda a sua extensão, ou não ramificado, sem caule principal alongado (figura $1 \mathrm{~A}, \mathrm{~L}$ ).

Huperzia christii, H. friburgensis (figura 1A), $H$. hemleri, $H$. intermedia, $H$. reflexa e $H$. treitubensis são espécies terrestres, com caule ereto a recurvado. Foram coletadas em campo rupestre, sendo Huperzia reflexa e $H$. treitubensis em locais úmidos (margem de rio) e abertos, $H$. christii em local aberto e as demais em locais úmidos e sombreados.

Huperzia fontinaloides, $H$. heterocarpon, $H$. hexasticha e $H$. quadrifariata (figura $1 \mathrm{~L}$ ) são epífitas e pendentes. Foram coletadas em mata de altitude, em locais sombreados e úmidos.

Quanto à morfologia, as folhas podem ser classificadas como homofilas, quando são uniformes, como no grupo de Huperzia reflexa (figura 1A-I); gradualmente heterofilas, quando são reduzidas gradualmente em direção ao ápice, como em $H$. treitubensis e no subgrupo de $H$. quadrifariata; heterofilas, quando são distintas. A heterofilia ocorre de duas maneiras: uma, quando as folhas nas porções terminais do caule são abruptamente diferentes do restante, o que só ocorre em Huperzia heterocarpon (figura 1R-T); outra, quando as folhas das porções basais (figura $1 \mathrm{M}$ ) são expandidas em relação às demais (figura $1 \mathrm{~N}-\mathrm{O}$ ), o que só ocorre em $H$. quadrifariata, nos espécimens de números de coletores Klein 3526 e Meireles 1203; em Brade 14191 as folhas são gradualmente heterofilas.

As folhas de todas as espécies estudadas são sésseis (figura 1C-D, F-G, I, K, M-N, R-T) e do tipo microfila, com uma única nervura (figura 2). A base, ou base e meio da folha são adpressos ao caule (figura 
$1 \mathrm{H}, \mathrm{N}-\mathrm{Q})$. Assim, no ponto onde uma folha deixa de ser adpressa, nasce outra, oposta ou não (figura $1 \mathrm{H}, \mathrm{N}-\mathrm{Q}$ ), fazendo com que os tecidos de caule e folha sejam contínuos ao longo da planta. Somente em Huperzia intermedia verificou-se que o caule não é totalmente adnato às folhas.

As espécies do grupo de Huperzia reflexa apresentam folhas voltadas para baixo, ou reflexas (figura 1A-B, H), de filotaxia helicoidal, com margens denteadas em dois espécimens de $H$. reflexa (Melo 13, Cardoso 5, figura 2) e em todos os espécimens de $H$. christii (figura 1D-E) e H. hemleri. Nas outras espécies, as margens são inteiras, como em Huperzia friburgensis (figura 1C). Quanto à forma, as folhas podem ser lanceoladas, como em Huperzia christii (figura 1D) e $H$. hemleri (figura 1I); lineareslanceoladas, como em $H$. friburgensis (figura 1C) e $H$. reflexa (figura $1 \mathrm{~F}$ ); e lineares em $H$. intermedia (figura $1 \mathrm{G}$ ).

As espécies do subgrupo de Huperzia quadrifariata apresentam folhas imbricadas, de filotaxia decussada ou subdecussada, com margens inteiras (figura $1 \mathrm{~L}-\mathrm{Q}$ ). Quanto à forma, são oval-aguçadas (figura $1 \mathrm{~N}-\mathrm{P}$ ) e, nos espécimens heterofilos de Huperzia quadrifariata, as folhas expandidas são oblongas (figura $1 \mathrm{M}$ ) e as não expandidas são oval-aguçadas (figura $1 \mathrm{~N}-\mathrm{Q}$ ).

Huperzia treitubensis, que pertence ao grupo de $H$. brongniartii, apresenta folhas imbricadas, apressas ao caule, de filotaxia helicoidal e lanceoladas (figura 1J).

Em Huperzia heterocarpon, do grupo de $H$. heterocarpon, as folhas são ereto-patentes, de filotaxia helicoidal, com margens inteiras (figura 1R-T), de ápice acuminado nas folhas do ápice caulinar (figura 1S) e lanceoladas do terço mediano até a base (figura 1R-S).

As espécies estudadas podem ter: a) esporângios desde o ápice do caule até a base, como em Huperzia treitubensis e nas espécies do grupo de $H$. reflexa, exceto em $H$. intermedia, que apresenta esporângios desde o ápice do caule até a base, mas com algumas regiões do caule sem esporângios; b) esporângios no ápice e meio do caule, como em $H$. heterocarpon ou c) esporângios apenas no ápice do caule, como nas espécies do subgrupo de $H$. quadrifariata.

Os esporofilos podem ser semelhantes às folhas vegetativas, nas espécies homofilas e gradualmente heterofilas (figura 1A-C), diferenciados apenas pela presença de um esporângio na axila; ou diferentes como em $H$. heterocarpon (figura 1R-T), espécie heterofila.

Em vista frontal, as células da epiderme foliar podem ter forma irregular ou ser retangulares (figuras 3-7) e alongadas, com o maior eixo paralelo ao eixo da folha, com paredes anticlinais sinuosas (figuras 3-5), retilíneas (figura 6), ou levemente sinuosas (figura 7), dependendo da espécie e da região da folha (ao longo das margens e/ou da nervura). A tabela 1 descreve a forma das células epidérmicas e as características das paredes anticlinais. Como Huperzia heterocarpon é heterofila, elaborou-se a tabela 2, com: esporofilos diferentes das folhas vegetativas e menores, esporofilos diferentes das folhas vegetativas e maiores, esporofilos semelhantes às folhas vegetativas.

As folhas são anfiestomáticas na maioria das espécies, epiestomáticas em Huperzia fontinaloides (figuras 3-4) e hipoestomáticas em H. hemleri (figura 5). Os estômatos estão distribuídos ao longo de toda margem foliar e ausentes na nervura (figura 6). A exceção deste padrão é Huperzia friburgensis: na face adaxial os estômatos estão em maior número no ápice da folha e em menor número na base, ou ausentes (figura 7). Foram observadas estriações nas células-guarda e 3-6 células periestomáticas (figuras 3,7).

Em secção transversal da folha, verificou-se que a epiderme é uniestratificada (figuras 8-12), com células de parede periclinal externa mais espessada na superfície abaxial que na adaxial (figuras 9-10), com invaginações na face externa das paredes periclinais externas. Em Huperzia fontinaloides, o espessamento da parede periclinal externa das folhas

Figure 1. Morphological aspects of Huperzia reflexa (Lam.) Trevis. species group (A-I), H. brongniartii (Spring) Trevis. species group (J-K), H. quadrifariata (Bory) Rothm. species group (L-Q) and H. heterocarpon (Fée) Holub species group (R-T). A-C. H. friburgensis (Nessel) B. Øllg. A. Habit. B. Stem portion, median region with sporangia. C. Leaf. D-E. H. christii (Silveira) Holub. D. Leaf. E. Detail. F. H. reflexa, leaf. G. H. intermedia Trevis., leaf. H- I. H. hemleri (Nessel) B. Øllg. H. Stem portion, median region with sporangia. I. Leaf. J-K. H. treitubensis (Silveira) B. Øllg. J. Leaf. K. Detail. L-O. H. quadrifariata. L. Habit. M. Expanded leaf at stem base. N. Detail. O. Stem portion, apical region with sporangia. P. H. hexasticha B. Øllg.\& P.G. Windisch, stem portion, apical region with sporangia. Q. H. fontinaloides (Spring) Trevis., stem portion, apical region with sporangia. R-T. H. heterocarpon. R. Vegetative leaf. S. Sporophyll similar to the vegetative leaf. T. Sporophyll different from the vegetative leaf (1 A-C - Sylvestre 1406b; D-E - Brade 3069; F - Konno 783; G - Soffiatti 39; H-I - Leitman 324; J-K - s. col. CESJ 27346; L-O - Meireles 2003; P - Salino 5616; Q - Rodrigues 72; R-T - Pita 273). 


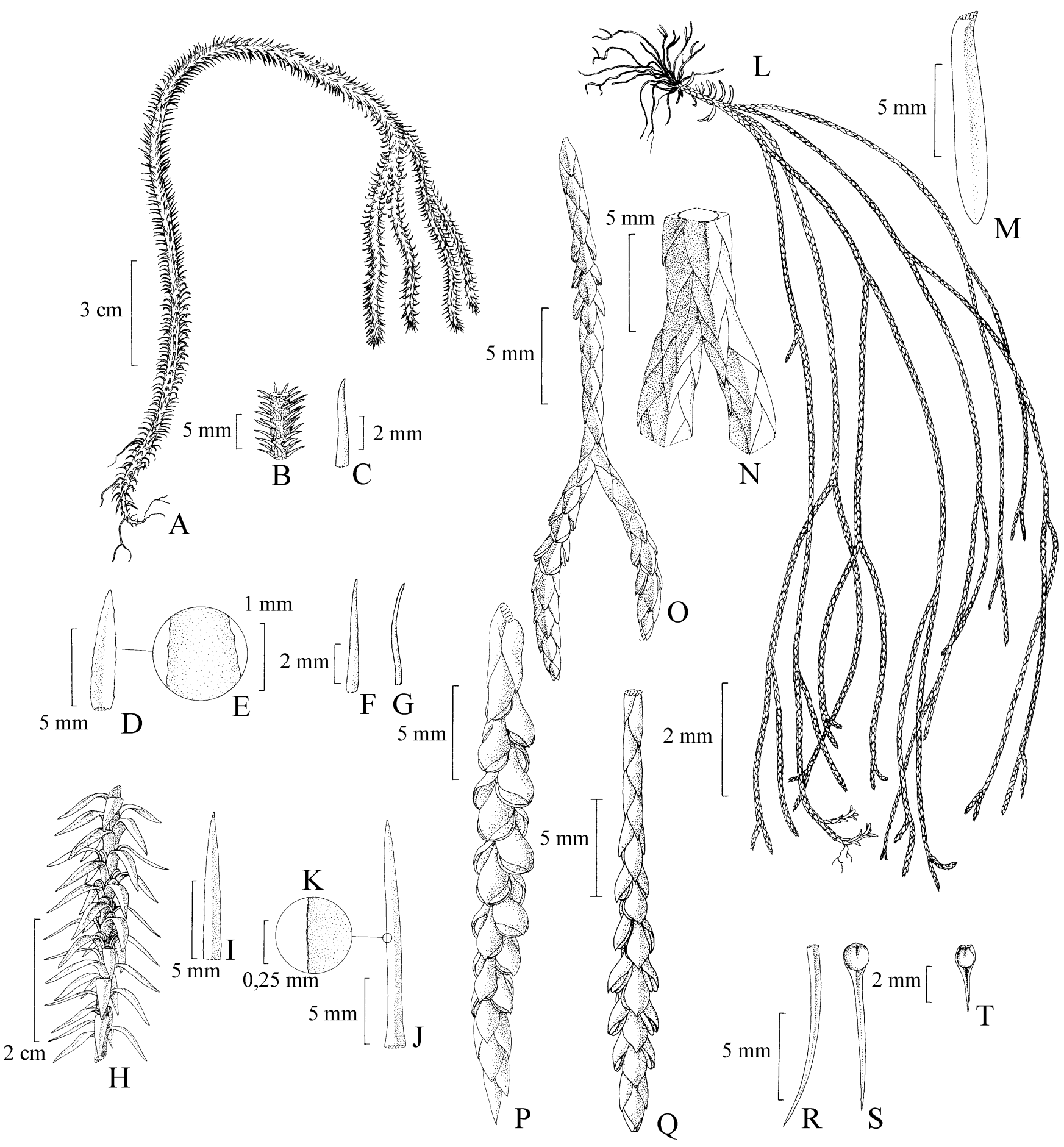

Figura 1. Aspectos morfológicos das espécies do grupo de Huperzia reflexa (Lam.) Trevis. (A-I), grupo de H. brongniartii (Spring) Trevis. (J-K), grupo de H. quadrifariata (Bory) Rothm. (L-O) e grupo de H. heterocarpon (Fée) Holub (R-T). A-C. H. friburgensis (Nessel) B. Øllg. A. Hábito. B. Parte do caule, região mediana com esporângios. C. Folha. D-E. H. christii (Silveira) Holub. D. Folha. E. Detalhe. F. H. reflexa, folha. G. H. intermedia Trevis., folha. H- I. H. hemleri (Nessel) B. Øllg. H. Parte do caule, região mediana com esporângios. I. Folha. J-K. H. treitubensis (Silveira) B. Øllg. J. Folha. K. Detalhe. L-O. H. quadrifariata. L. Hábito. M. Folha expandida da base do caule. N. Detalhe. O. Parte do caule, região apical com esporângios. P. H. hexasticha B. Øllg.\& P.G. Windisch, parte do caule, região apical com esporângios. Q. H. fontinaloides (Spring) Trevis., parte do caule, região apical com esporângios. R-T. H. heterocarpon. R. Folha vegetativa. S. Esporofilo semelhante à folha vegetativa. T. Esporofilo diferente da folha vegetativa (A-C - Sylvestre 1406b; D-E - Brade 3069; F - Konno 783; G - Soffiatti 39; H-I - Leitman 324; J-K - s. col. CESJ 27346; L-O - Meireles 2003; P - Salino 5616; Q - Rodrigues 72; R-T- Pita 273). 
da base do caule é mais acentuado que nas folhas das outras regiões, e não apresenta invaginações. Em Huperzia heterocarpon, as invaginações são menos numerosas (figuras 9-10). As células da epiderme na superfície adaxial são maiores que na abaxial (figuras 8-12). O teste com Sudan IV demonstrou que a cutícula é delgada (figura 13) em todas as espécies analisadas. Os estômatos apresentam células-guarda com paredes espessadas, cristas (figura 13), muitos cloroplastos e câmara subestomática bastante ampla (figura 13).

O mesofilo caracteriza-se por apresentar

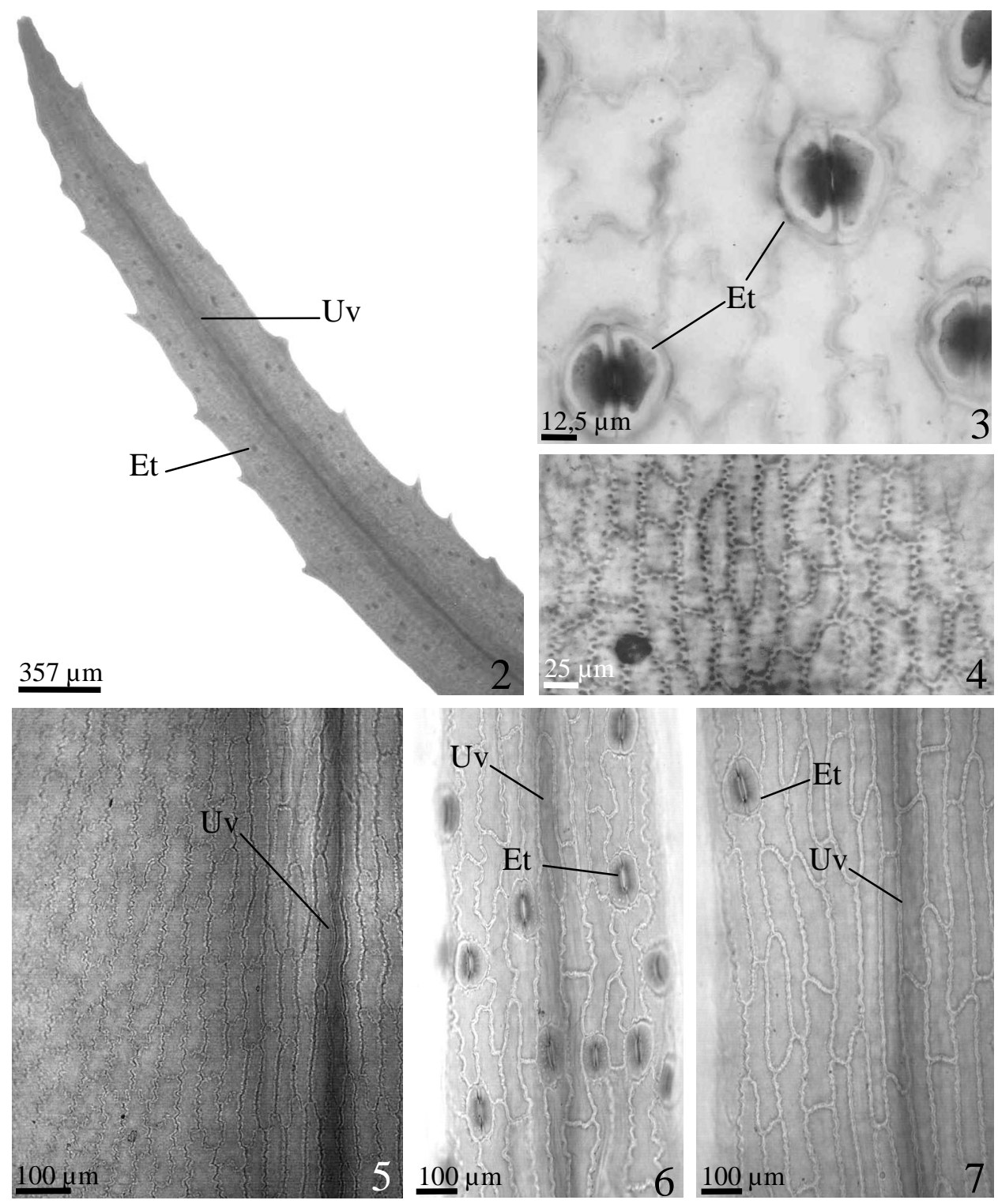

Figuras 2-7. Superfícies foliares de espécies de Huperzia, material diafanizado. 2. Huperzia reflexa (Lam.) Trevis., superfície adaxial. 3-4. H. fontinaloides (Spring) Trevis. 3. Superfície adaxial, com estômatos (Et). 4. Superfície abaxial, sem estômatos. 5. H. hemleri (Nessel) B. Øllg., superfície adaxial, sem estômatos. 6-7. H. friburgensis (Nessel) B. Øllg., 6. Superfície abaxial, região basal. 7. Superfície adaxial, região apical. (Uv = unidade vascular) (2 - Cardoso 5; 3-4 - Rodrigues 72; 5 - Leitman 324; 6-7 - Sylvestre1406b).

Figures 2-7. Foliar surfaces of Huperzia species, clarified material. 2. Huperzia reflexa (Lam.) Trevis., adaxial surface. 3-4. H. fontinaloides (Spring) Trevis. 3. Adaxial surface with stomata (Et). 4. Abaxial surface without stomata. 5. H. hemleri (Nessel) B. Øllg., adaxial surface without stomata. 6-7. H. friburgensis (Nessel) B. Øllg., 6. Abaxial surface, basal region. 7. Adaxial surface, apical region. (Uv = vascular unit) (2 - Cardoso 5; 3-4 - Rodrigues 72; 5. Leitman 324; 6-7 - Sylvestre 1406b). 
Tabela 1. Forma e características das paredes anticlinais das células epidérmicas em espécies de Huperzia. Células retangulares (R), células de contorno irregular (IR), paredes anticlinais retilíneas (RT), paredes anticlinais levemente sinuosas (LS), paredes anticlinais sinuosas (S). (1= grupo H. brongniartii (Spring) Trevis.; 2 = grupo H. reflexa (Lam.) Trevis.; $3=$ subgrupo H. quadrifariata (Bory) Rothm.).

Table 1. Shape and features of anticlinal walls of the epidermal cells of the Huperzia species. Rectangular cells (R), irregular cells (IR), straight anticlinal walls (RT), slightly sinuous anticlinal walls (LS), sinuous anticlinal walls (S). (1 = H. brongniartii (Spring) Trevis. group; $2=$ H. reflexa (Lam.) Trevis. group; $3=$ H. quadrifariata (Bory) Rothm. subgroup).

\begin{tabular}{|c|c|c|c|c|}
\hline \multirow[t]{2}{*}{ Espécie (localização) } & \multicolumn{2}{|c|}{ Superfície adaxial } & \multicolumn{2}{|c|}{ Superfície abaxial } \\
\hline & Margem & Nervura & Margem & Nervura \\
\hline H. treitubensis (1) & $\mathrm{IR} / \mathrm{S}$ & $\mathrm{IR} / \mathrm{S}$ & $\mathrm{IR} / \mathrm{S}$ & R/LS \\
\hline H. christii (2) & $\mathrm{IR} / \mathrm{S}$ & $\mathrm{IR} / \mathrm{S}$ & $\mathrm{R} / \mathrm{S}$ & R/LS \\
\hline H. friburgensis (2) & $\mathrm{R} / \mathrm{RT}$ & $\mathrm{R} / \mathrm{RT}$ & R/LS & $\mathrm{R} / \mathrm{RT}$ \\
\hline H. hemleri (2) & $\mathrm{R} / \mathrm{S}$ & $\mathrm{R} / \mathrm{S}$ & R/LS & $\mathrm{R} / \mathrm{S}$ \\
\hline H. intermedia(2) & $\mathrm{R} / \mathrm{S}$ & $\mathrm{R} / \mathrm{S}$ & $\mathrm{R} / \mathrm{LS}$ & $\mathrm{R} / \mathrm{S}$ \\
\hline H. reflexa (2) & $\mathrm{R} / \mathrm{S}$ & $\mathrm{R} / \mathrm{S}$ & $\mathrm{R} / \mathrm{RT}$ & $\mathrm{R} / \mathrm{RT}$ \\
\hline H. fontinaloides (3) & $\mathrm{IR} / \mathrm{S}$ & $\mathrm{R} / \mathrm{S}$ & $\mathrm{R} / \mathrm{S}$ & $\mathrm{R} / \mathrm{S}$ \\
\hline H. hexasticha (3) & $\mathrm{R} / \mathrm{S}$ & $\mathrm{R} / \mathrm{S}$ & $\mathrm{IR} / \mathrm{S}$ & $\mathrm{R} / \mathrm{S}$ \\
\hline H. quadrifariata(3) & $\mathrm{IR} / \mathrm{S}$ & $\mathrm{IR} / \mathrm{RT}$ & $\mathrm{IR} / \mathrm{RT}$ & $\mathrm{R} / \mathrm{RT}$ \\
\hline
\end{tabular}

parênquima clorofiliano lacunoso com células braciformes e, ao redor da nervura, células de contorno arredondado (figuras 8-13), que constituem a porção interna do mesofilo. As células do parênquima clorofiliano lacunoso, que estão em contato com a epiderme, apresentam uma disposição radial, em relação ao sistema vascular (figuras 8, 11-12), uma vez que as projeções de suas células fazem contato com a parede periclinal interna da epiderme, ou quando não fazem contato se direcionam para a mesma. Essa disposição é menos marcante em Huperzia heterocarpon e H. reflexa, pois as projeções das células são menores.

$\mathrm{Na}$ base da folha, o parênquima clorofiliano lacunoso está localizado apenas na face abaxial; pois na face adaxial, que está adnata ao caule, ocorre um parênquima de células semelhantes às do córtex do próprio caule, devido à continuidade de tecidos entre estes dois órgãos. A figura 14 mostra claramente esta continuidade de tecidos, em secção trasversal.

A endoderme apresenta espessamento em " $U$ ", sendo mais visível nos traços foliares presentes no córtex do caule.

As folhas possuem uma única nervura, que parte do sistema vascular do caule sem deixar lacunas (figuras 14-15). Os traços foliares se originam junto aos pólos de protoxilema (figura 16) e, aparentemente, formamse a partir do periciclo, com poucos elementos vasculares diferenciados (figuras 16-17); a medida que se aproxima da superfície do caule, em direção à folha, aumenta o número de elementos traqueais diferenciados. Na folha, o traço (ou unidade vascular) já está totalmente diferenciado (figura 18, Uv). O sistema

Tabela 2. Forma e características das paredes anticlinais das células epidérmicas de Huperzia heterocarpon (Fée) Holub. Células retangulares (R), células de contorno irregular (IR), paredes anticlinais retilíneas (RT), paredes anticlinais levemente sinuosas (LS), paredes anticlinais sinuosas (S).

Table 2. Shape and features of anticlinal walls of the epidermal cells of Huperzia heterocarpon (Fée) Holub. Rectangular cells (R), irregular cells (IR), straight anticlinal walls (RT), slightly sinuous anticlinal walls (LS), sinuous antilcinal walls (S).

\begin{tabular}{|c|c|c|c|c|}
\hline \multirow[t]{2}{*}{ Tipo de folha } & \multicolumn{2}{|c|}{ Superfície adaxial } & \multicolumn{2}{|c|}{ Superfície abaxial } \\
\hline & Margem & Nevura & Margem & Nervura \\
\hline Esporofilo diferente das folhas vegetativas e menores & $\mathrm{R} / \mathrm{S}$ & $\mathrm{R}-\mathrm{IR} / \mathrm{S}$ & $\mathrm{R} / \mathrm{LS}$ & R-IR/LS \\
\hline Esporofilo diferente das folhas vegetativas e maiores & $\mathrm{IR} / \mathrm{S}$ & IR/S & $\mathrm{IR} / \mathrm{S}$ & IR/RT \\
\hline Esporofilo semelhante às folhas vegetativas & $\mathrm{R} / \mathrm{S}$ & $\mathrm{R} / \mathrm{S}$ & $\mathrm{R} / \mathrm{S}$ & $\mathrm{R} / \mathrm{S}$ \\
\hline Folhas vegetativas & $R / S$ & $\mathrm{R} / \mathrm{S}$ & $\mathrm{R} / \mathrm{S}$ & $\mathrm{R} / \mathrm{S}$ \\
\hline
\end{tabular}



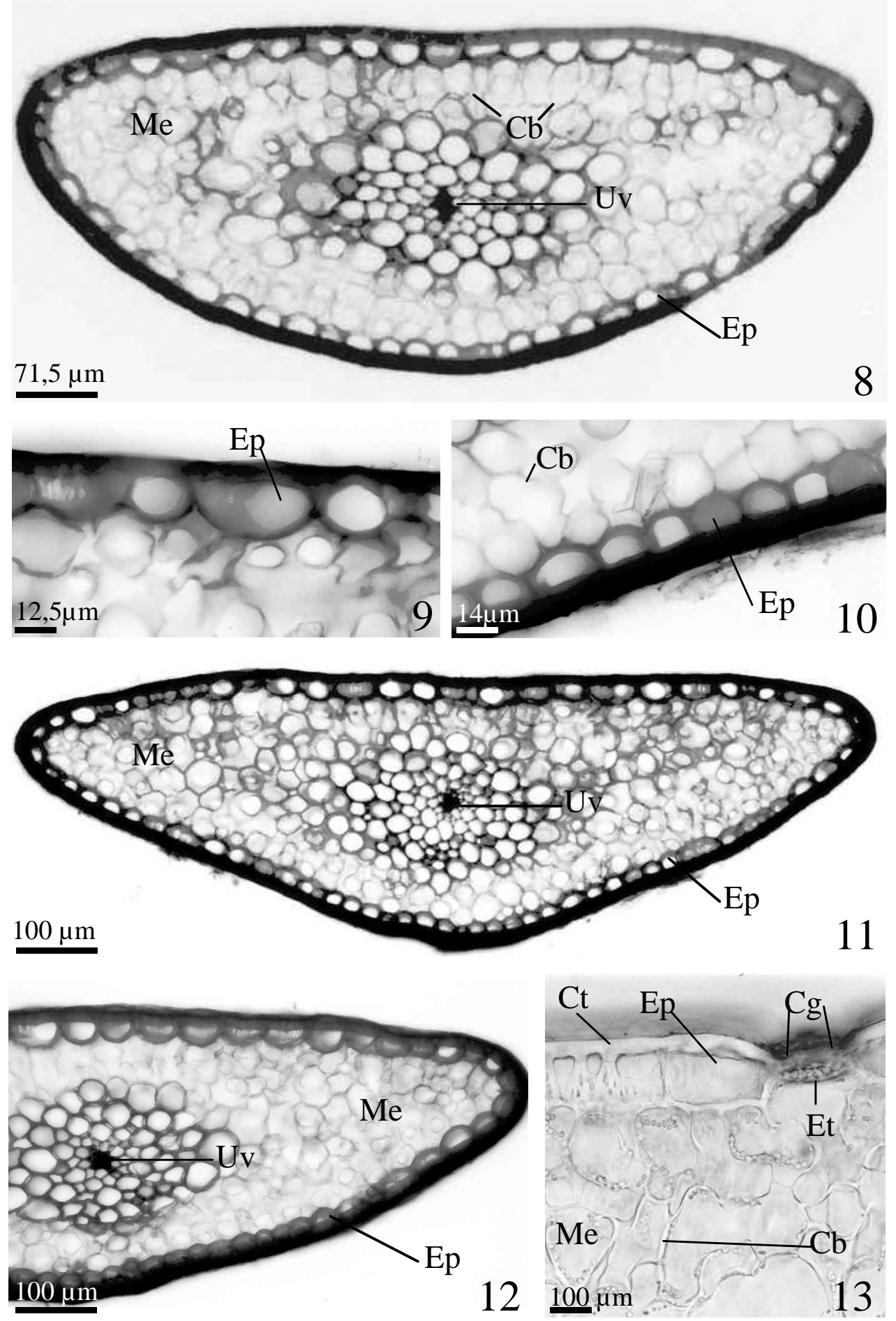

Figuras 8-13. Secção transversal das folhas de Huperzia heterocarpon (Fée) Holub (8-12) e H. quadrifariata (Bory) Rothm. (13). 8-11. Esporofilos. 9-10. Detalhe da epiderme (Ep), superfícies adaxial e abaxial respectivamente; note as células braciformes $(\mathrm{Cb})$ próximas à epiderme. 12. Folha vegetativa da região mediana do caule. 13. Detalhe da secção transversal da folha; cutícula $(\mathrm{Ct})$ e estômato (Et) com Sudan IV. (Cg = células-guarda; $\mathrm{Me}=$ mesofilo; Uv = unidade vascular) (8-12 - Pita 273, 13 - Klein 3526).

Figures 8-13. Cross section of Huperzia heterocarpon (Fée) Holub (8-12) and H. quadrifariata (Bory) Rothm. (13) leaves. 8-11. Sporophylls. 9-10. Epidermis (Ep) detail, adaxial and abaxial surfaces respectively; note the braciform cells $(\mathrm{Cb})$ near the epidermis. 12. Vegetative leaf from median stem region. 13. Detail of leaf cross section; cuticle (Ct) and stomata (Et) with Sudan IV. $(\mathrm{Cg}=$ guard cells; $\mathrm{Me}=$ mesophyll; $\mathrm{Uv}=$ vascular unit $)(8-12-$ Pita 273, 13 - Klein 3526). 
vascular, internamente à endoderme, é formado pelo periciclo, xilema e floema, este quase indistinto, interno ao xilema.

Em secção longitudinal, verificou-se que as células do mesofilo, que formam camadas concêntricas ao redor da unidade vascular, são alongadas (figura 19, cabeças de seta). Em secção longitudinal e no material que foi macerado, observou-se que os elementos traqueais são traqueídes de protoxilema, a maioria com espessamento anelado e algumas com espessamento helicoidal (figura 19). Não há metaxilema. Os elementos de floema são células alongadas, estreitas e de extremidades afiladas, com corpos lipídicos (figura 19 , setas) e não formam calose, como foi verificado no teste com azul de resorcina; não foram observadas áreas crivadas.

Na figura 20, ainda em secção longitudinal, observase a continuidade de tecidos entre caule e folha e que o traço foliar só aparece na folha próximo ao nível em que a lâmina foliar torna-se independente do caule (Tf). As células da epiderme são alongadas em ambas as superfícies (figura 21) e verifica-se, com mais precisão, as invaginações da parede periclinal externa (figura 21, cabeças de seta) e as extensões das células do parênquima clorofiliano que fazem contato com a epiderme (figura 21, cabeças de seta), sendo que nestas últimas pode-se observar que estas células são braciformes e de formas irregulares.

Os esporângios originam-se na axila dos esporofilos, onde permanecem após o seu desenvolvimento (figuras 22-23). São pedicelados e reniformes. A deiscência ocorre por uma abertura transversal, ou estômio (figura 23), que divide os esporângios em duas valvas iguais (figura 23), portanto, são isovalvados. O pedicelo não é vascularizado (figura 24); o tecido é formado por células de parede primária delgada, diferente das células dos tecidos adjacentes (figura 24).

Em vista frontal de uma valva do esporângio, observa-se que o estômio é constituído por uma camada de células de paredes anticlinais e periclinal interna espessadas e lignificadas (figura 25). As demais células da camada externa do esporângio são alongadas radialmente em relação ao pedicelo, com paredes laterais sinuosas e espessadas quando próximas do estômio, e retilíneas e menos espessadas quando próximas do pedicelo. Tais células também apresentam paredes anticlinais espessadas e lignificadas. Estas características variam entre as espécies estudadas: em Huperzia christii, $H$. friburgensis (figura 26), $H$. hexasticha, $H$. fontinaloides, $H$. reflexa e $H$. treitubensis as paredes são sinuosas e espessadas até a metade da valva do esporângio, na outra metade tornam-se gradativamente retilíneas e menos espessadas. Em Huperzia heterocarpon, $H$. hemleri (figura 27) e $H$. intermedia são sinuosas e espessadas na maior parte do esporângio e retilíneas e menos espessadas quando próximas ao pedicelo. Em Huperzia quadrifariata, a situação é inversa, as paredes são sinuosas e espessadas apenas próximas ao estômio e retilíneas e menos espessadas na maior parte do esporângio.

Em secção transversal, verificou-se que o esporângio é constituído por 3-4 camadas de células de paredes lignificadas: Huperzia fontinaloides, $H$. hexasticha e $H$. quadrifariata apresentam 3 camadas de células e as demais espécies apresentam 4 camadas.

A formação dos esporos ocorre em tétrades (figura 28); os núcleos são bem evidentes (figura $28, \mathrm{Nu}$ ). Apresentam lesão trilete (figura 29) e ornamentação foveolada, com pontoações, ou foveolada-fossulada (figura 30), em que as pontoações se unem formando sulcos.

Os testes realizados com cloreto de zinco iodado, floroglucinol acidificado e Steinmetz demonstram presença de lignina no xilema e nas paredes do esporângio. O floroglucinol acidificado e o Sudan IV reagiram com substâncias presentes no floema, sendo que o Sudan IV, especificamente, identificou a presença de substâncias lipídicas. O Sudan IV também identificou a presença de substâncias lipídicas na cutícula.

Todas estas características podem ser relacionadas em uma chave dicotômica, que resume as principais diferenças e similaridades entre os grupos e as espécies estudadas: 

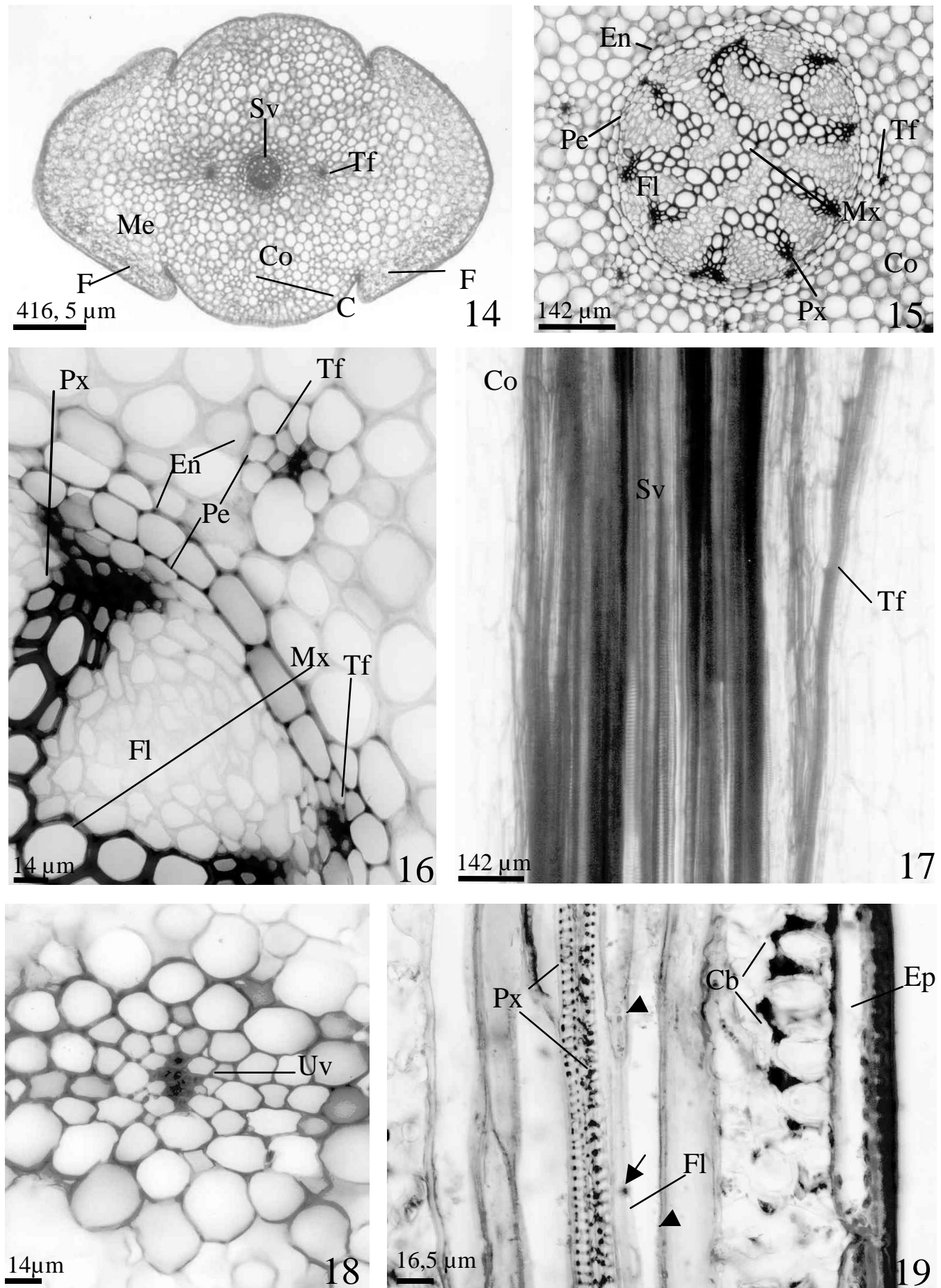

Figuras 14-19. Secções transversais e longitudinais de caule e folha de Huperzia quadrifariata (Bory) Rothm. (14), H. friburgensis (Nessel) B. Øllg. (15-17, 19) e H. heterocarpon (Fée) Holub (18). 14. Secção transversal de caule (C) com duas folhas (F), região apical. 15. Sistema vascular do caule, secção transversal. 16. Detalhe de 15. 17. Sistema vascular do caule, secção longitudinal.18. Folha com uma unidade vascular (Uv), com poucas traqueídes de protoxilema. 19. Secção longitudinal de folha, detalhe. ( cabeças de seta $=$ células do mesofilo ao redor do sistema vascular, seta $=$ corpos lipídicos; $\mathrm{Cb}=$ células braciformes; $\mathrm{Co}=$ córtex $; \mathrm{En}=$ endoderme $; \mathrm{Ep}=$ epiderme; $\mathrm{Fl}=$ floema; $\mathrm{Me}=$ mesofilo; $\mathrm{Mx}=$ metaxilema $; \mathrm{Pe}=$ periciclo $; \mathrm{Px}=$ protoxilema; $\mathrm{Sv}=$ sistema vascular; $\mathrm{Tf}=$ traço foliar $(14$ - Klein 3526; 15-17, 19 - Sylvestre 1406b; 18 - Pita 273). 
Chave de identificação baseada em características morfológicas das espécies de Huperzia estudadas

1. Filotaxia helicoidal, folhas reflexas, esporângios com 4 camadas de células

2. Folhas hipoestomáticas Huperzia hemleri

2. Folhas anfiestomáticas

3. Folhas com estômatos distribuídos ao longo de toda margem foliar na superfície abaxial e com poucos estômatos na superfície adaxial, distribuídos no ápice e na base, ou ausentes nesta região Huperzia friburgensis

3. Folhas com estômatos distribuídos ao longo de toda margem foliar em ambas as faces

4. Paredes das células do esporângio sinuosas e espessadas na maior parte superior da valva, e retilíneas e espessadas apenas quando próximas do pedicelo Huperzia intermedia

4. Paredes das células do esporângio sinuosas e espessadas até a metade superior da valva e, na outra metade, gradativamente retilíneas e menos espessadas.

5. Células epidérmicas de formato retangular em ambas as superfícies foliares; paredes anticlinais retilíneas na superfície abaxial .. Huperzia reflexa

5. Células epidérmicas de formato irregular na superfície adaxial e retangulares na superfície abaxial; paredes anticlinais sinuosas na superfície abaxial Huperzia christii

1. Filotaxia oposta, folhas adpressas ao caule, esporângios com 3 camadas de células

6. Folhas epiestomáticas

Huperzia fontinaloides

6. Folhas anfiestomáticas

7. Paredes das células do esporângio sinuosas e espessadas até a metade que inclui o estômio da valva e, na outra metade, gradativamente retilíneas e menos espessadas Huperzia hexasticha

7. Paredes das células do esporângio sinuosas e espessadas próximas ao estômio e retilíneas e pouco espessadas na maior parte da valva Huperzia quadrifariata

\section{Discussão}

As espécies de Huperzia estudadas apresentam folhas do tipo microfila, como é característico de Lycopodiaceae e de Lycopsida, de uma maneira geral (Ogura 1972, Gifford \& Foster 1989).

Segundo Gifford \& Foster (1989) e Kenrick \& Crane (1997), uma das características marcantes das Lycopsida é a associação de um esporângio com um esporofilo. Em Lycopodiaceae, os esporofilos têm funções diferentes e podem ser modificados ou semelhantes às folhas vegetativas. Em Lycopodiella, Lycopodium e Phylloglossum são bastante diferenciados, reunidos em estróbilos terminais e estão correlacionados com a função do esporângio, pois o protege durante a sua formação e a produção dos esporos e murcham logo após a sua deiscência e dispersão (Øllgaard 1987). Em Huperzia, Sporne (1966) e Øllgaard (1987) discutem que existe pouca correlação entre a função e o comportamento dos esporofilos, como também foi observado nas espécies do presente trabalho. Os esporofilos não são modificados, não oferecem proteção aos esporângios e estes, depois de abertos, não afetam a condição dos esporofilos, que permanecem verdes e fotossintetizantes após a dispersão dos esporos (Sporne 1966, Øllgaard 1987).

Quanto à morfologia, existem situações em que os esporofilos podem ou não ser diferentes das folhas vegetativas (Øllgaard 1987), como foi observado em Huperzia heterocarpon neste trabalho. Esta heterofilia é considerada como um caráter derivado em Huperzia, que ocorreu pela redução das folhas de ancestrais homofilos (Øllgaard 1987). Algumas espécies são homofilas por reversão secundária, como exemplificado

Figures 14-19. Cross and longitudinal sections of Huperzia quadrifariata (Bory) Rothm. (14), H. friburgensis (Nessel) B. Øllg. $(15-17,19)$ and H. heterocarpon (Fée) Holub (18) leaf and stem. 14. Stem (C) cross section, with two leaves (F), apical region. 15. Stem vascular system, cross section. 16. Detail of 15. 17. Stem vascular system, longitudinal section. 18. Leaf with a vascular unit (Uv), with few protoxylem tracheids. 19. Leaf longitudinal section, detail. (arrow heads $=$ mesophyll cells around vascular unit; arrow = lipidic bodies; $\mathrm{Cb}=$ braciform cells; $\mathrm{Co}=$ cortex; $\mathrm{En}=$ endodermis; $\mathrm{Ep}=$ epidermis; $\mathrm{Fl}=$ phloem; $\mathrm{Me}=$ mesophyll; $\mathrm{Mx}=$ metaxylem; $\mathrm{Pe}=$ pericicle $\mathrm{Px}=$ protoxylem; $\mathrm{Sv}=$ vascular system; $\mathrm{Tf}=$ foliar trace $)(14-$ Klein 3526; 15-17, $19-$ Sylvestre 1406b, 18 - Pita 273). 


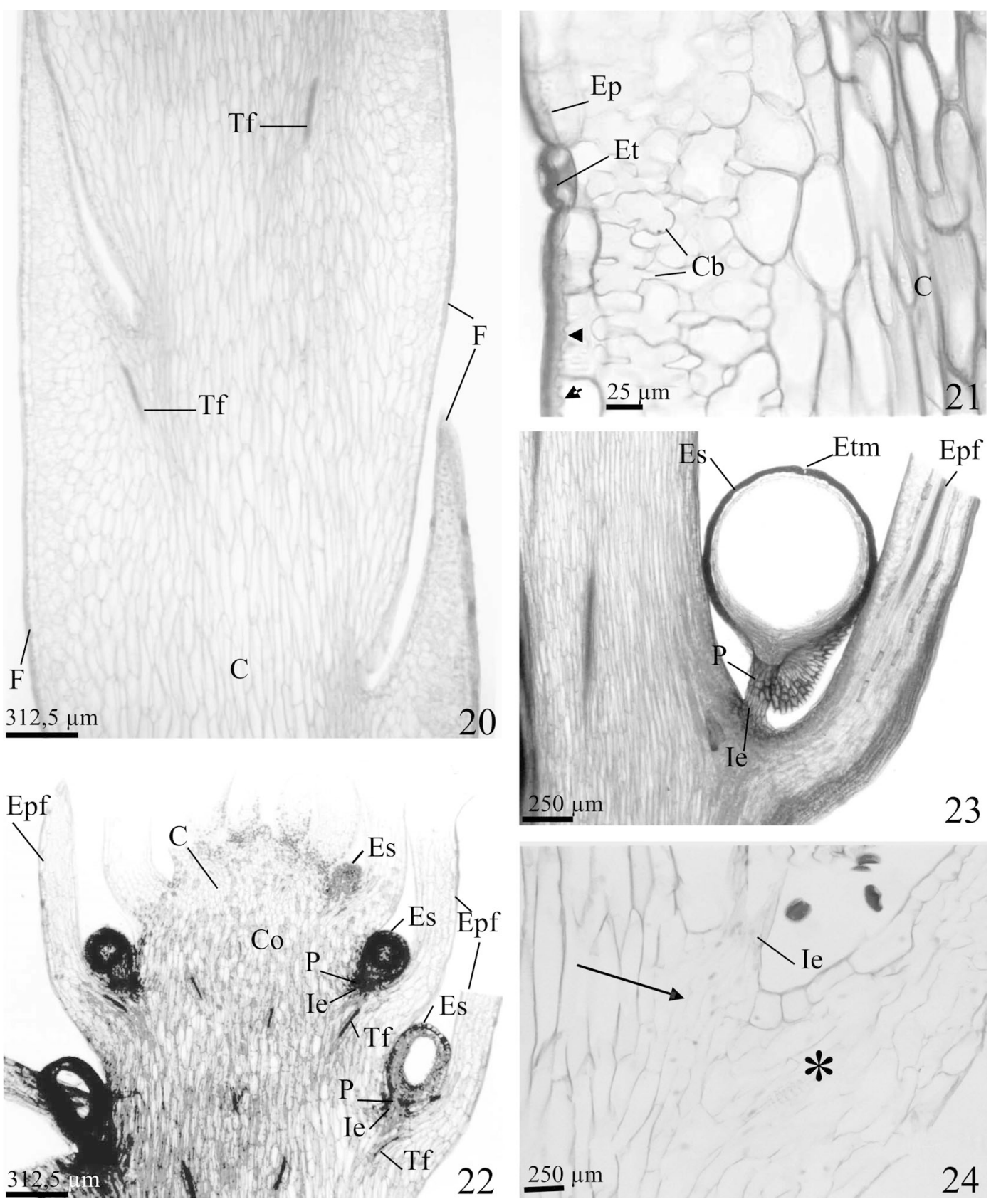

Figuras 20-24. Secções longitudinais de fragmentos de caule, com folhas e esporângios, de Huperzia quadrifariata (Bory) Rothm. (20-21), H. friburgensis (Nessel) B. Øllg. (22), H. treitubensis (Silveira) B. Øllg. (23) e H. heterocarpon (Fée) Holub (24). 20. Região mediana do caule; observa-se a continuidade dos tecidos de caule (C) e folha (F). 21. Detalhe da folha; as células da epiderme (Ep) são alongadas, as cabeças de seta indicam as ondulações da parede periclinal externa; note as células braciformes (Cb) próximas à epiderme. 22. Ápice caulinar, mostrando a inserção (Ie) dos esporângios (Es). 23. Região mediana do caule, com esporângio. 24. Detalhe da inserção do esporângio: células do pedicelo (seta) diferentes das células do esporofilo $(*)(C o=$ córtex; Epf = esporofilo; Et = estômato; Etm = estômio; $\mathrm{P}=$ pedicelo do esporângio; $\mathrm{Tf}=$ traço foliar $)(20-21$ - Klein 3526; 22 - Sylvestre 1406b; 23 - s.col. CESJ 27346; 24 - Pita 273).

Figures 20-24. Longitudinal sections of stem portions, with leaves and sporangia of Huperzia quadrifariata (Bory) Rothm. (20-21), H. friburgensis (Nessel) B. Øllg. (22), H. treitubensis (Silveira) B. Øllg. (23) and H. heterocarpon (Fée) Holub (24). 20. Stem median region; note the continuity of stem $(C)$ and leaf $(F)$ tissues. 21. Leaf detail; the epidermis (Ep) cells are elongated, the arrow heads indicate the external periclinal waviness; note the braciform cells $(\mathrm{Cb})$ near the epidermis. 22. Stem apex with sporangia (Es) insertion (Ie). 23. Stem median region with sporangia. 24. Sporangia insertion detail: pedicel cells (arrow) different from the sporophyll cells $(*)(\mathrm{Co}=$ cortex; $\mathrm{Epf}=$ sporophyll; $\mathrm{Et}=$ stomata; $\mathrm{Etm}=$ stomium; $\mathrm{P}=$ sporangia pedicel; $\mathrm{Tf}=$ foliar trace $)(20-21$ - Klein 3526; 22 - Sylvestre 1406b; 23 - s.col. CESJ 27346; 24 - Pita 273). 
por Øllgaard (1987) em Huperzia fontinaloides e $H$. quadrifariata, que apresentam folhas oblongas na base da planta, além das folhas oval-aguçadas, ou apresentam somente as folhas oval-aguçadas. Esta variação levou alguns autores a considerarem indivíduos com folhas expandidas e sem as mesmas como espécies distintas, sendo colocadas em secções diferentes
(Øllgaard 1987). No presente trabalho, observou-se que dois espécimens, dos três analisados, de Huperzia quadrifariata apresentam tais folhas expandidas na base do caule, e em $H$. fontinaloides não se verificou esta característica.

Baseando-se nestes fatos, pode-se dizer que, neste gênero, a redução gradual ou abrupta das folhas não
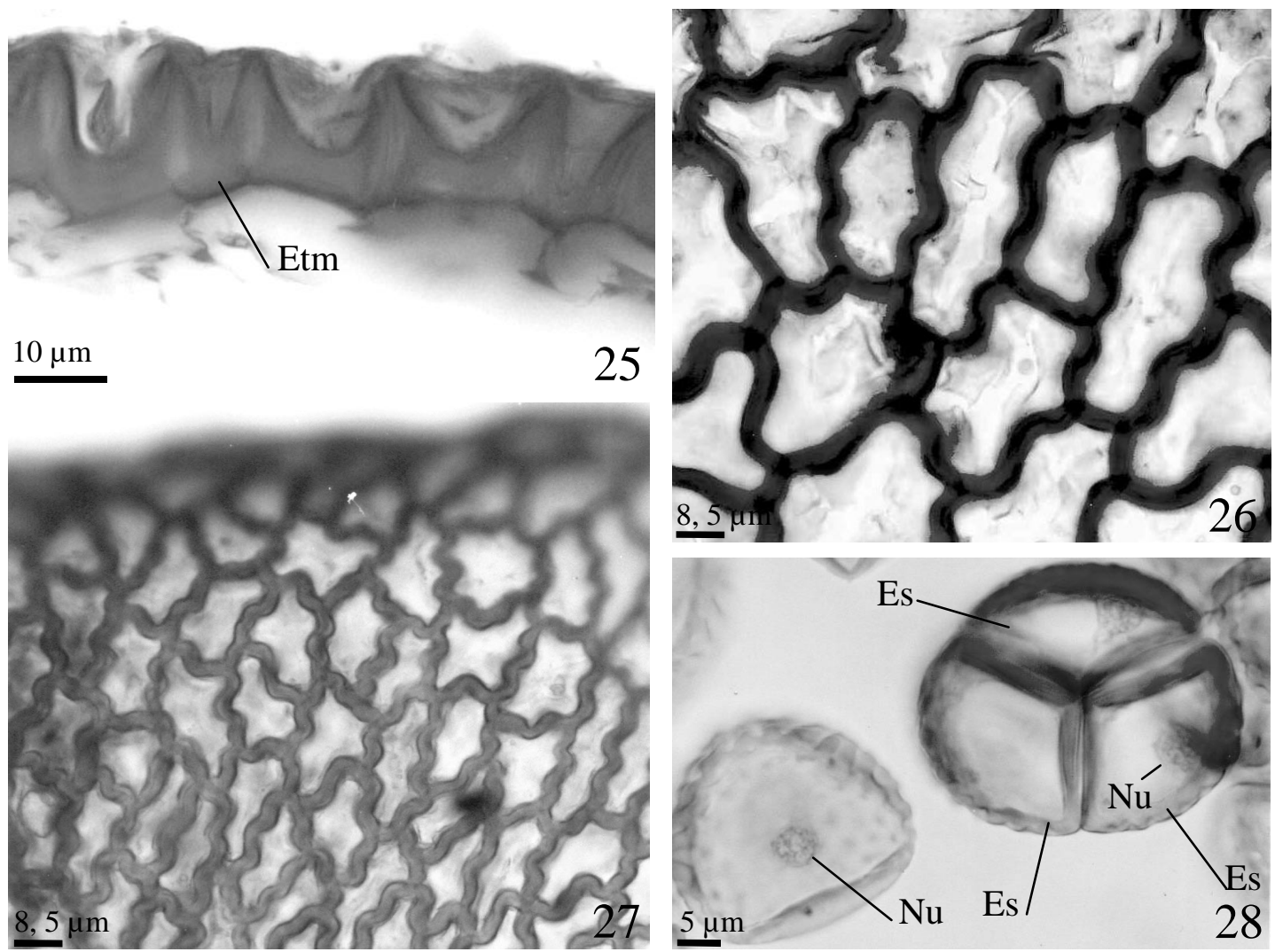

$10 \mu \mathrm{m}$

25
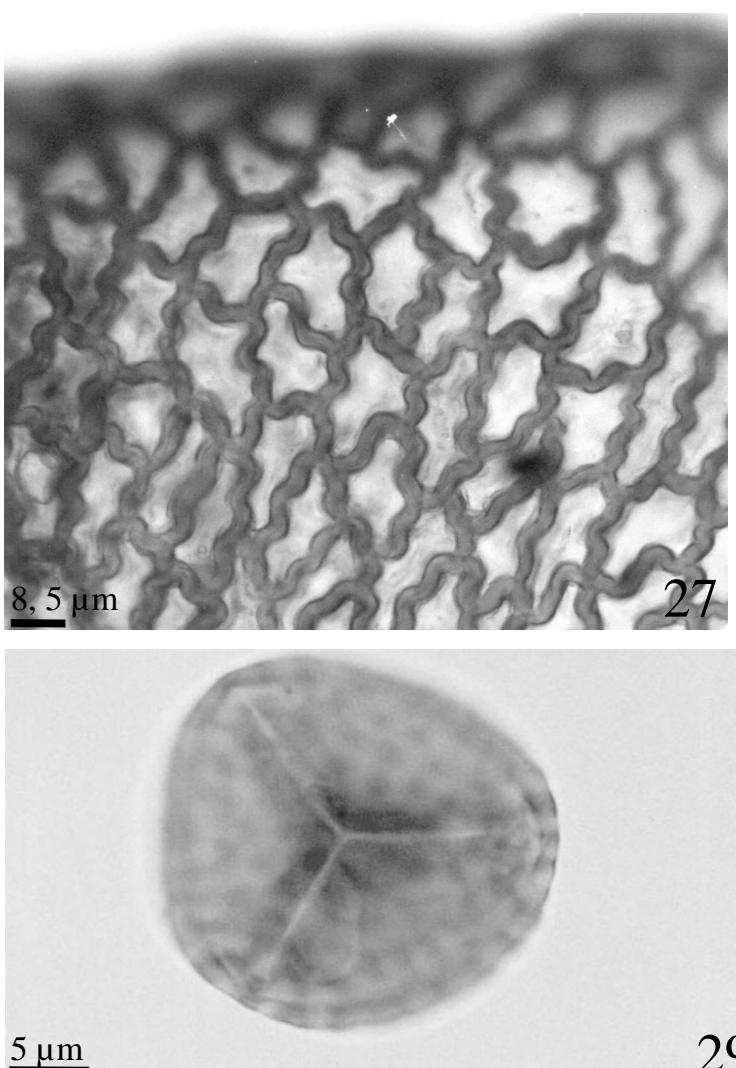

$5 \mu \mathrm{m}$

28

$5 \mu \mathrm{m}$

29

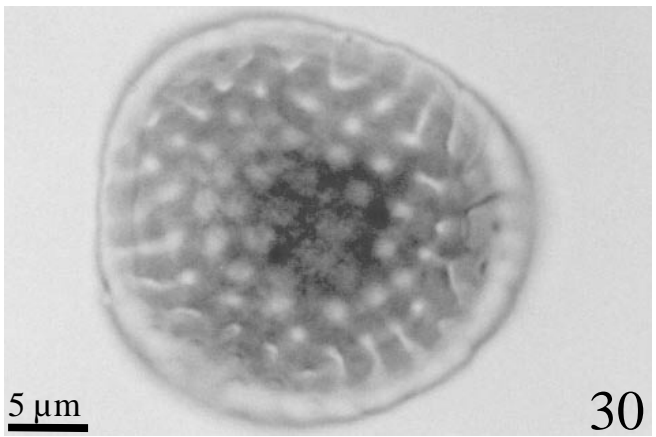

Figuras 25-30. Esporângios e esporos de Huperzia hemleri (Nessel) B. Øllg. (25, 27), H. friburgensis (Nessel) B. Øllg. (26) e H. treitubensis (Silveira) B. Øllg. (28-30). 25. Detalhe das células do estômio (Etm). 26-27. Detalhe das células da epiderme do esporângio. 28. Esporos (Es) e o núcleo (Nu). 29. Esporo em vista proximal, detalhe da lesão trilete. 30. Esporo em vista distal, detalhe da ornamentação da parede. (25, 27 - Leitman 324; 26 - Sylvestre 1406b; 28-30 - s.col. CESJ 27346).

Figures 25-30. Sporangia and spores of Huperzia hemleri (Nessel) B. Øllg. (25, 27), H. friburgensis (Nessel) B. Øllg. (26) and H. treitubensis (Silveira) B. Øllg. (28-30). 25. Stomium cells detail (Etm). 26-27. Sporangia epidermis cells detail. 28. Spores (Es) and nucleus $(\mathrm{Nu})$. 29. Spore proximal view, trilete laesura detail. 30. Spore distal view, wall ornamentation detail. (25, 27 - Leitman 324; 26 - Sylvestre 1406b; 28-30 - s.col. CESJ 27346). 
está estritamente associada ao início da região fértil, ou com a presença de esporofilos e esporângios (Øllgaard 1987), como foi observado em Huperzia heterocarpon.

No grupo de Huperzia reflexa, as espécies H. christii, H. hemleri e dois dos espécimens examinados de $H$. reflexa apresentam margens denteadas, enquanto nas demais espécies as margens são inteiras. A variação desta característica neste grupo já foi descrita anteriormente por Øllgaard $(1987,1992)$ e, aparentemente, não tem nenhum significado em termos taxonômicos.

Em relação ao ambiente, de uma maneira geral, as espécies analisadas neste trabalho passam por períodos de escassez hídrica e de nutrientes. As espécies epífitas foram coletadas em mata de altitude, onde a água só está disponível após chuvas, ou quando derivada de orvalho e neblina (Benzing 1990). No dossel, o movimento do ar é muito maior do que próximo ao solo e, por isso, as condições são desfavoráveis, ou a disponibilidade hídrica é muito baixa (Benzing 1990). Como crescem diretamente nos troncos, não existe um substrato do qual as raízes possam retirar os nutrientes minerais. Por esta razão, dependem do acúmulo de detritos vegetais e animais, poeira, e dos resíduos que estão associados com a casca dos forófitos.

As espécies terrestres estudadas foram coletadas em campos rupestres e de altitude, onde o substrato é arenoso ou rochoso, raso, pobre em nutrientes, com pouca capacidade de retenção de água (Giulietti et al. 1987) e atinge altas temperaturas superficiais (Joly 1970). As plantas estão sujeitas a uma alta amplitude térmica ao longo do dia e a altos índices de insolação; em campos rupestres, há um período de seca de quatro a cinco meses (Joly 1970). A água da neblina e da condensação, provavelmente, é importante para as plantas destes ambientes (Giulietti et al. 1987).

Jones (1987) considera o grupo das pteridófitas como de grande sucesso na adaptação para ambientes sujeitos a escassez hídrica. Segundo ele, estas plantas se adaptam de duas maneiras, basicamente: alterando seu metabolismo ou através de características morfológicas específicas.

As espécies de peteridófitas estudadas no presente trabalho apresentam células epidérmicas com paredes anticlinais de contorno sinuoso a retilíneo, em vista frontal. Avery (1933) relaciona às sinuosidades da epiderme ao estresse em que as plantas estão sujeitas no seu desenvolvimento. Esau (1965) acredita que a variação das sinuosidades possa ocorrer por fatores ambientais, sendo menos onduladas em ambientes mais secos e mais onduladas em ambientes mais úmidos.
Rolleri (1972) e Chu (1974) também observaram estas sinuosidades nas células epidérmicas das espécies por eles estudadas. Segundo Rolleri (1972), elas podem ser formadas na parede primária e na lamela mediana, ou apenas na parede primária, e somente no primeiro caso as sinuosidades são ditas verdadeiras. Tais estruturas foram aqui denominadas de invaginações. No presente trabalho, todas as espécies de Huperzia apresentam sinuosidades verdadeiras, pois, lamela mediana e parede primária são sinuosas.

Também foram observadas, em secção transversal, invaginações na face interna da parede periclinal externa das células epidérmicas. Rolleri (1972) encontrou formações semelhantes nas margens foliares das espécies saxícolas por ela estudadas, interpretadas como reforço mecânico adquirido em resposta ao ambiente em que vivem, em vales e campos de altitude.

Segundo a maioria dos estudos, a localização dos estômatos varia entre as espécies de Lycopodiaceae. Por exemplo, as espécies que Toursarkissian (1971) analisou são anfiestomáticas e epiestomáticas e Rolleri (1972) encontrou espécies anfiestomáticas, epiestomáticas e hipoestomáticas. A folha de Huperzia mandiocana foi classificada por Toursarkissian (1971) como epiestomática e por Rolleri (1972) como hipoestomática. Talvez os espécimens não estejam identificados corretamente, ou ocorra mesmo esta variação intra-específica. Na maioria das espécies estudadas neste trabalho, as folhas são anfiestomáticas. De acordo com Fahn \& Cutler (1992), a presença de estômatos em ambas as superfícies aumenta a condutividade de $\mathrm{CO}_{2}$, sendo comum em plantas de ambientes com pouca disponibilidade hídrica, como naquelas que foram aqui estudadas.

Segundo Rolleri (1972), Ogura (1972) e Chu (1974), os estômatos estão localizados ao longo das margens foliares, não ocorrendo na superfície acima da região da nervura, corroborando com os dados encontrados no presente trabalho. Segundo Rolleri (1972), apresentam 3-6 células periestomáticas, que não são células subsidiárias propriamente ditas, como foi verificado no presente estudo. Chowdhury (1937 apud Ogura 1972) encontrou estriações finas e radiais na parede externa das células-guarda em algumas espécies por ele estudadas. Neste trabalho, todas as espécies apresentam estômatos com estriações radiais.

Erkson (1892 apud Ogura 1972) descreveu as células do mesofilo das Lycopodiaceae como alongadas, irregulares, alongadas-paliçádicas e lacunosas, ou em forma de "H" e lacunosas. Provavelmente, as células em forma de "H" correspondem às que Freier (1959) 
denominou de raquimorfas ao descrever as células do parênquima clorofiliano de espécies de gramíneas, e que se assemelham com as que foram encontradas nas espécies de Huperzia estudadas. Estas células são providas de braços e apófises, por meio dos quais se põem em contato com as células vizinhas. Os espaços intercelulares são determinados pelas constrições dessas células. No presente trabalho, estas células foram denominadas de braciformes.

Embora os autores (Toursarkissian 1971, Ogura 1972, Rolleri 1972) não tenham identificado a presença da endoderme, nas espécies estudadas neste trabalho ela foi identificada, inclusive envolvendo o traço foliar, desde a saída do estelo do caule até a folha.

Huperzia mostrou um excelente material para a comprovação da continuidade entre os tecidos dos diferentes órgãos, em particular, entre o caule e a folha. Especialmente nas seções longitudinais, foi possível observar esta continuidade exatamente como observado por Menezes et al. (2003) em monocotiledôneas. A evidência da continuidade entre os tecidos dos diferentes órgãos levou esses autores a reconhecer a presença da endoderme e do periciclo em todas as folhas de Spermatophyta confirmado, neste trabalho, nas folhas de Huperzia.

A unidade vascular das espécies estudadas é sempre única, com periciclo descontínuo e com poucos elementos vasculares, como é típico das microfilas (Sporne 1966). O xilema está representado por algumas traqueídes de protoxilema aneladas e helicoidais, de diferenciação endarca, embora Wilder (1970) tenha identificado traqueídes reticuladas. Entre as pteridófitas, o floema é bastante reduzido, com corpos lipídicos e sem calose (Warmbrodt \& Evert 1974a, b). Nas espécies de Huperzia estudadas neste trabalho, os corpos lipídicos identificam o floema.

Os esporângios das espécies de Huperzia estudadas não são vascularizados. De uma maneira geral, nas licopsidas recentes, não há traço vascular ou vestígios de tecido procambial na base do esporângio (Sporne 1966, Ogura 1972, Gifford \& Foster 1989, Gensel 1992, dentre outros). De acordo com Sykes (1908, apud Gensel 1992), existem células lignificadas no pedicelo que fazem contato com as células ao redor da unidade vascular do esporofilo, funcionando, provavelmente, como um tecido de transfusão. Estas células não foram observadas nos pedicelos dos esporângios estudados, o tecido apresenta somente células parenquimáticas de paredes delgadas, mas diferentes das demais células do esporofilo e das células do córtex do caule. De acordo com as observações aqui realizadas, ao que tudo indica, o transporte de nutrientes ocorre por células especializadas para tal função.

Øllgaard (1975) encontrou padrões diferentes de formas de células, espessamento e ornamentação do esporângio nos diferentes gêneros da família. Os dados deste autor referentes à Huperzia, ou seja, epiderme sinuosa, e moderada a fortemente lignificada, foram confirmados no presente trabalho.

Com relação à morfologia dos esporos, as análises mais abrangentes quanto à família foram feitas por Wilce (1972) e Tryon \& Lugardon (1991). Wilce (1972) reconheceu três grupos de esporos em Lycopodiaceae e, dentro desses três grupos, tipos diferentes. Tendo como base esta análise, Tryon \& Lugardon (1991) fizeram uma revisão dos esporos dos quatro gêneros da família. De uma maneira geral, a cicatriz dos esporos é trilete (Wilce 1972, Tryon \& Lugardon 1991). Segundo os mesmos autores, a ornamentação da parede dos esporos de Huperzia é foveolada ou fossulada, de contorno subglobuloso a subtriangular, como foi observado nas espécies estudadas neste trabalho.

A ornamentação da parede dos esporos de Huperzia é o caráter mais conservativo do gênero, considerando o tamanho, a ampla distribuição e a diversidade ecológica do grupo (Tryon \& Lugardon 1991).

Embora a morfologia externa e interna das folhas vegetativas, esporofilos e esporângios das espécies estudadas seja muito simples, foi possível elaborar uma chave de identificação com características que delimitaram os grupos de espécies e as espécies sensu Øllgaard (1987). Os caracteres que separaram os dois grupos foram a filotaxia, a posição da folha em relação ao caule e o número de camadas dos esporângios. Huperzia heterocarpon e H. treitubensis, que foram utilizadas como comparação, também apresentam filotaxia helicoidal e esporângios com 4 camadas de células, como o grupo de $H$. reflexa. Entretanto, as espécies deste grupo apresentam uma característica muito marcante, que é a presença de folhas reflexas, diferente do que ocorre em Huperzia heterocarpon e H. treitubensis.

Não foram identificadas características anatômicas que pudessem diferenciar as estratégias adaptativas para os ambientes terrestre e epifítico, provavelmente pelo fato da maioria das espécies terrestres estudas pertencerem ao grupo de Huperzia reflexa, que sofreu reversão secundária para o ambiente terrestre, segundo estudos filogenéticos de Wikström et al. (1999).

A partir destes dados, acredita-se que mais estudos morfológicos do gênero Huperzia poderão revelar 
aspectos importantes que auxiliarão no conhecimento e na taxonomia do mesmo.

Agradecimentos - Ao Conselho Nacional de Desenvolvimento Científico e Tecnológico (CNPq), pela concessão da bolsa à primeira autora; aos curadores dos Herbários do Instituto de Botânica (SP), do Departamento de Botânica da Universidade de São Paulo (SPF) e Leopoldo Krieger (CESJ), por terem cedido material para o presente estudo; ao curador do Herbário do Jardim Botânico do Rio de Janeiro (RB), pelo empréstimo de exsicatas e por ter cedido material para o presente estudo.

\section{Referências bibliográficas}

AVERY, G. S. 1933. Structure and development of the tobacco leaf. American Journal of Botany 20:565-592.

BENZING, D.H. 1990. Vascular epiphytes: general biology and related biota. Cambridge University Press, Cambridge.

BRUCE, J.G. 1976. Development and distribution of mucilage canals in Lycopodium. American Journal of Botany 63:481-491.

CHEADLE, V.I., GIFFORD, E.M.J.R. \& ESAU, K. 1953. A staining combination for phloem and contiguous tissues. Stain Technology 28:49-53.

CHU, M.C. 1974. A comparative study of foliar anatomy of Lycopodium species. American Journal of Botany 61:681-692.

COSTA, A.F. 1970. Farmacognosia v.3. Fundação Calouste Gulbenkian, Lisboa.

ESAU, K. 1965. Anatomy of seed plants. $2^{\text {nd }}$ ed. John Wiley \& Sons, New York.

FAHN, A. \& CUTLER, D.F. 1992. Xerophytes. Encyclopedia of plant taxonomy. Gebrüder Borntraeger, Berlin.

FOSTER, A.S. 1949. Practical plant anatomy. D. van Nostrand Company, Princetown.

FREIER, F. 1959. Las células clorenquimáticas del mesófilo de las gramíneas. Revista Argentina de Agronomia 26:1-16.

GENSEL, P.G. 1992. Phylogenetic relantionships of the zosterophylls and lycopsids: evidence from morphology, paleoecology, and cladistic methods of inference. Annals of the Missouri Botanical Garden 79:450-473.

GIFFORD, E.M. \& FOSTER, A.S. 1989. Morphology and evolution of vascular plants. $3^{\text {rd }}$ ed. Freeman and Co., New York.

GIULIETTI, A.M., MENEZES, N.L., PIRANI, J.R., MEGURO, M. \& WANDERLEY, M.G.L. 1987. Flora da Serra do Cipó: caracterização e lista das espécies. Boletim de Botânica da Universidade de São Paulo 9:1-151.

HACKNEY, F.M.V. 1950. A review of and contribution to knowledge of Phylloglossum drumondii Kunze. Proccedings of the Linnean Society New South Wales 75:133-152.
JENSEN, W.A. 1962. Botanical histochemistry, principles and pratice. W.H.Freeman, San Francisco.

JOHANSEN, D.A. 1940. Plant microtechnique. McGraw-Hill, New York.

JOLY, A.B. 1970. Conheça a vegetação brasileira. Edusp e Polígono, São Paulo.

JONES, D.L. 1987. Encyclopaedia of ferns: an introduction to ferns, their structure, biology, economic importance, cultivation and propagation. Timber Press, Portland.

KENRICK, P. \& CRANE, P.R. 1997. The origin and early diversification of land plants: a cladistic study. Smithsonian Institution Press, Washington.

KRAUS, J.E. \& ARDUIN, M. 1997. Manual básico de métodos em morfologia vegetal. Edur, Seropédica.

KRAUS, J.E., SOUSA, H.C., REZENDE, M.H., CASTRO, N.M., VECCHI, C. \& LUQUE, R. 1998. Astra blue and basic fuchsin double staining of plant materials. Biotechnic \& Histochemistry 73:235-243.

LERSTEN, N.R. \& CURTIS, J.D. 1988. Secretory reservois (ducts) of two kinds in giant ragweed (Ambrosia trifida; Asteraceae). American Journal of Botany 75:1313-1323.

MENEZES, N.L., SILVA, D.C. \& MELO-DE-PINNA, G.F.A. 2003. Folha. In Anatomia Vegetal (B. Appezzato-deGlória \& S.M. Carmelo-Guerreiro, eds.). Editora UFV, Viçosa, p.303-325.

OGURA, Y. 1972. Comparative anatomy of vegetative organs of the Pteridophytes. Gebrüder Bornträger, Berlin.

ØLLGAARD, B. 1975. Studies in Lycopodiaceae, I. Observations on the structure of the sporangium wall. American Fern Journal 65:19-27.

$\varnothing$ LLGAARD, B. 1987. A revised classification of the Lycopodiaceae sen. lat. Opera Botanica 92:153-178.

ØLLGAARD, B. 1992. Neotropical Lycopodiaceae - an overview. Annals of the Missouri Botanical Garden 79:687-717.

ØLLGAARD, B. 1996. Neotropical Huperzia (Lycopodiaceae) - distribution of species richness. In Pteridology in Perspective. (J.M. Camus, M. Gibby \& R.J. Johns, eds.). Royal Botanic Gardens, Kew, p.93-100.

ØLLGAARD, B. \& WINDISCH, P.G. 1987. Sinopse das licopodiáceas do Brasil. Bradea 5:1-43.

PRYER, K.M., SCHNEIDER, H., SMITH, A.R., CRANFILL, R., WOLF, P.G., HUNT, J.S. \& SIPES, S.D. 2001. Horsetails and ferns are a monophyletic group and the closest relatives to seed plants. Nature 409:618-621.

ROLLERI, C. 1972. Morfologia comparada de las especies de "Lycopodium" (Pteridophyta-Lycopodiaceae) para el noroeste argentino. Revista del Museo de la Plata 12:223-317.

ROLLERI, C. 1975. A new species of Lycopodium from Peruvian Andes. American Fern Journal 65:3-6.

SPORNE, K.R. 1966. The morphology of pteridophytes. The structure of ferns and allied plants. $2^{\text {nd }} e d$. Hutchinson University Library, London. 
STRITTMATTER, C.G.D. 1973. Nueva técnica de diafanización. Boletin de la Sociedad Argentina de Botanica 15:126-129.

TOURSARKISSIAN, M. 1971. Las Lycopodiaceae del Noroeste de Argentina - Estudio Sistemático y Anatómico. Anais da Academia Brasileira de Ciências 43:191-207.

TRYON, A.F. \& LUGARDON, B. 1991. Spores of the pteridophyta: surface, wall structure, and diversity based on electron microscope studies. Springer-Verlag, Berlin.

WARMBRODT, R.D. \& EVERT, R.F. 1974a. Structure and development in the stem of Lycopodium lucidulum. American Journal of Botany 61:267-277.
WARMBRODT, R.D. \& EVERT, R.F. 1974b. Structure of the vascular parenchyma in the stem of Lycopodium lucidulum. American Journal of Botany 61:437-443.

WIKSTRÖM, N., KENRICK, P. \& CHASE, M. 1999. Ephiphytism and terrestrialization in tropical Huperzia (Lycopodiaceae). Plant Systematics and Evolution 218:221-243.

WILCE, J.H. 1972. Lycopod spores, I. General spore patterns and the generic segregates of Lycopodium. American Fern Journal 62:65-79.

WILDER, G.J. 1970. Structure of tracheids in three species of Lycopodium. American Journal of Botany 57:1093-1107. 